\title{
Cognition and thinking on Applied Optics course's reformation and innovation
}

Jingjing Chen, Feng Ji, Zhijian Liu, Haojie Xia, Shuangbao Shu

Jingjing Chen, Feng Ji, Zhijian Liu, Haojie Xia, Shuangbao Shu, "Cognition and thinking on Applied Optics course's reformation and innovation," Proc. SPIE 10452, 14th Conference on Education and Training in Optics and Photonics: ETOP 2017, 104524G (16 August 2017); doi: 10.1117/12.2267820

SPIE Event: 14th Conference on Education and Training in Optics and Photonics, ETOP 2017, 2017, Hangzhou, China 


\title{
Cognition and Thinking on Applied Optics Course's Reformation and Innovation
}

\author{
Chen Jingjing ${ }^{a}$, Ji Feng ${ }^{a}$, Liu Zhijian ${ }^{\mathrm{a}}$, Xia Haojie ${ }^{\mathrm{a}}$, Shu Shuangbao ${ }^{\mathrm{a}}$ \\ ${ }^{1}$ School of Instrument Science and Opto-Electronics Engineering, Hefei University of Technology, \\ Hefei, Anhui 230009, China
}

\begin{abstract}
The course of "Applied Optics" is professional and foundational for the specialty of photo-electric information and engineering. According to the characteristics of the specialty, the teaching contents, teaching means, innovations and appraisal methods are mainly discussed in this paper. Firstly, one of the most difficult part to comprehend, the Fermat principle is taken as an example in the teaching content. By using the development history of optics and interesting natural phenomenon, students' understanding of the optical knowledge can be enhanced. Secondly, in various means of teaching art, ZEMAX provides students with a platform of training innovative consciousness and engineering capacity, and it make high cohesion in teaching and scientific research. Thirdly, in the teaching innovation, photoelectric contest can stimulate students' innovative thinking, innovation awareness, and cultivate undergraduate students' optics, mechanics, electricity, numerology integrated design capabilities. Lastly, the reform in the appraisal methods guide students from focusing on the examination results to pay attention to the learning process. Eventually, students' study interest has improved, demand of the engineering practice has adapted, and the well teaching effect has realized.
\end{abstract}

Keywords: Applied Optics, Fermat principle, Innovation, development history of optics

\section{INTRODUCTION}

There have been many calls for the reform of the course of the Applied Optics. Although the development of China's optics can be traced back to 3000 years ago, and history books have recorded why people can see, the connection between seeing things and the light is studied. But until 1952 the university began to systematically learn the knowledge of optics firstly, when the establishment of Specialty of Optical Instrument of Zhejiang University for the first time in china. Since then, the opt-electric information science and engineering specialty of other colleges and universities have been successive established.

Applied Optics, the professional course, was opened for the first batch of Zhejiang University optical instrument professional students, in optical professional learning. In Hefei University of Technology, the applied optics, not only the professional required course of the "opt-electric information science and engineering specialty" and the "Measuring and controlling technology and instrument specialty", but also one of the most important courses in the discipline of optical engineering. It is not only the prerequisite course of the subsequent courses, but also can constitute a relatively complete optical system of theory to practice with physical optics, image quality evaluation technology, optical experiment, the optical design course. Applied optics teaching not only laid the foundation for the follow-up professional courses, but also try to develop students' critical thinking and problem-solving ability [1-2]. For such an important professional basic 
course, we need to constantly explore and study the application of optical teaching content and teaching methods, and continuously improve the teaching effect and teaching quality, so as to achieve teaching objectives, improve students' innovative ability.

\section{PROBLEM ON THE COURSE OF TEACHING}

In our school, the course of "applied optics" is opened in the first semester of the second year, the credits are 4 credits, and the class times are 48 hours. At the time, students are busy with the theoretical knowledge learning of basic courses (such as Mathematics, English), and learning "applied optics" is the first contact between students and professional basic courses. Students are more attentive and curious about this course. As a result of high school physics discipline adjustment in these years, students known very little knowledge of optics, i.e., they almost complete lack of related knowledge, and they also very unfamiliar with optical engineering problems. Therefore, the choice of teaching content, teaching methods, innovations and teaching methods must be first considered by teachers.

Because students know little about optical knowledge, while the "applied optics" contains a lot of content, there are

many hard nuts to crack during the teaching of theoretical knowledge such as the combination of the speculative knowledge with practical application, the concepts which defined strictly and abstract, lots of symbol, difficult to remember, various formulae, easy confusion and mistakes in the application. The above leading to the students generally feel difficult to learn this course. In order to solve these problems, we try to raise students' interest in teaching content through interesting questions, emphasize visualization, promote students' cognition, emphasize self-exploration and practice, and improve students' awareness[3-5]. We through the above several aspects of the reform and experiment to improve students' learning enthusiasm and the teaching effect of applied optics

\section{CONTENT OF COURSES}

Currently in optical teaching, some teachers mainly instill the textbook content of textbooks, and teach the contents literally, boring aspects and tedious formulae make students feel boring even tired in class. Students feel the optics lack of charm, and then the excitation and cultivation of interests are hampered. Therefore, in the teaching process, we must first mobilize the students' interest in the course, so that students have a strong thirst for knowledge. In the classroom, if we can bring in interesting issues according the specific content of the teaching to attract students' interest and attention of students, the analytical thinking, creativity and problem solving skills of all students will be stimulated. We come from the following two aspects of the introduction of the problem.

\subsection{The development history of optics}

The development of optics has a long history, for example, the "Yangsui(bronze mirror placed in the sun to generate enough heat to ignite dry grass)" was invented more than 3000 years ago by the greater China with the most ancient civilization. The earliest optical device---"Yangsui", which used to focus the sun light to make a fire, is a concave mirror which made by bronze ware. In China the study of optics can dates back to ancient time. Early in the Warring States period, the reason why we can see things mentioned in the history books, "fire light eye", that is the eye can sees all things because the existence of light. But in the whole stage of optics research in China, systematic research in this field is lack, just the record of actual events, i.e., the observation and recording, and the principle behind it is rarely explored. So, it is a pity that the systemic research and development optical haven't developed in China. 
Nowadays, with the fast development and wide application of optical technology, the optics theory have been continuously improved, optical knowledge is still in research up to now. The power of human wisdom is awe-inspiring as the long and tortuous process. The essence of light is the most compelling argument in the history of optics. What is the nature of light? Particles or waves? The arguments have lasted for thousands of years which from the scientific revolution era until the 20th century. During that period, a variety of views flourishing, the argument between the debates is war clouds, flames everywhere, and the whole process ups and downs, full of suspense. Until the 20th century view was finally unified: light is both particle and wave. This history of arguments on the light essence can arousing students' interest, attracting the attention of students, and promoting students' thinking. On the other hand, such as the ether medium occupies more than two thousand years in the history of optical. In more than two centuries people have considered the ether is real, whether the great scientists Kepler or the great scientists Maxwell believes the ether exists. Until 1881, with the help of the velocity of light measuring experiments by Michelson, the inexistence of the ether was proved. In addition, the theory that light is particle which proposed by greatest scientist Newton has been proved to be wrong. So we can encourage students to think, to look at scientific knowledge with a critical eye, to believe only rely on their own logical thinking and the experiment, and don't superstitious in academic authority by the optical history.

In the next place, some of the course contents are extremely hard to understand, for example, the "Fermat principle". Fermat principle is the following: a ray going in a certain particular path has the property that if we make a small change (say a one percent shift) in the ray in any manner whatever, say in the location at which it comes to the mirror, or the shape of the curve, or anything, there will be no first-order change in the time; there will be only a second-order change in the time. In other words, the principle is that light takes a path such that there are many other paths nearby which take almost exactly the same time. In many cases the Fermat principle is expressed as the least time principle. The following is another difficulty with the principle of least time. With Snell's theory we can "understand" light. Light goes along, it sees a surface, and it bends because it does something at the surface. The idea of causality, that it goes from one point to another, and another, and so on, is easy to understand. But the principle of least time is a completely different philosophical principle about the way nature works. Instead of saying it is a causal thing, that when we do one thing, something else happens, and so on, it says this: we set up the situation, and light decides which is the shortest time, or the extreme one, and choose that path. But what does it do, how does it find out? Does it smell the nearby paths, and check them against each other? By using optical development history, perhaps the easiest way to understand the principle. Although geometrical optics is just an approximation, it is of very great importance technically and of great interest historically. We shall present this course more historically than some of the others in order to give some idea of the development of a physical theory of physical idea.

Now let us study the behavior of light when it hits various materials. The simplest object is a mirror, and the law for a mirror is that when the light hits the mirror, it does not continue in a straight line, but bounces off the mirror into a new straight line, which changes when we change the inclination of the mirror. The question for the ancients was, what is the relation between the two angles involved? This is a very simple relation, discovered long ago. That is a simple enough proposition, but a more difficult problem is encountered when light goes from one medium into another, for example from air into water; here also, we see that it does not go in a straight line. This also puzzled the ancients for a long time, and here they never found the answer! It is, however, one of the few places in all of Greek physics that one may find any experimental results listed. This, then, is one of the important steps in the development of physical law: first we observe an effect, then we measure it and list it in a table; then we try to find the rule by which one thing can be connected with 
another. The experimental data was made in 140 A.D., but it was not until 1621 that Willebrord Snell finally found the rule connecting the two angles, the Snell's law.

Now in the further development of science, we want more than just a formula. First we have an observation, then we have numbers that we measure, then we have a law which summarizes all the numbers. But the real glory of science is that we can find a way of thinking such that the law is evident. The first way of thinking that made the law about the behavior of light evident was discovered by Fermat in about 1650, and it is called Fermat's principle. Next we will first show that this is true for the case of the mirror, that this simple principle contains both the law of straight-line propagation and the law for the mirror, and then show that this is true for refraction. Review of history and expectation of the future make it easy to understand the principle, and provides an illustration to help students understand this relationship. This history can arousing students' interest, attracting the attention of students, and promoting students' thinking.

\subsection{Interesting natural phenomenon}

Light, actually is a very familiar concept for everyone. If there is no light we can't see this colorful world. Furthermore, optical knowledge is widely applied in the daily life, science and engineering project. The interesting phenomenon, unique phenomenon and novel natural phenomenon could be proposed before the relevant chapters as questions. We could take advantage of the student's curiosity to stimulate their learning interest. Many classical Chinese poetry were created according by the optical characteristics. So the well-known poems can be used to inspire the student's creative thinking when they study the basic principle of light. And also, does the causes of the beautiful rainbow and the multicolored soap bubbles in the daily life the same? Furthermore, the scattering theory is another example, the question of "why the sky is blue?" can be mentioned, and the cause of the blue sky can be proved by experiments in science classes.

\section{TEACHING MEANS - ZEMAX}

Although multimedia instruction is now popularized, which we can display animation and video to students. But after several years of "Applied Optics" course teaching, it has been found that in addition to the blackboard and chalk, the sketches and multimedia instruction are still have many deficiencies [6-8]. For example, because of "Applied Optics" containing many abstract mathematic principles and giving emphasis to experiments at the same time, so it is a typical major course which integrates theory with practice. We should focus on demonstration, experiment, on-site observation, optical design software simulation and other intuitive teaching methods to enable students thinking and exploring in an intuitive, image-simulated environment. However, it is well known that the conditions required for the optical experiment are very high, and the experimental phenomena can be summed up in a weak, refined, and tiny way. And due to constraints in the classroom it will be difficult to demonstrate or exhibit correct results. These traditional teaching methods are very mature, but it also shows a relatively backward. This creates a mismatch in optical theory and experiment on teaching time and space, and it has been very significantly affect the application of the optical effect of teaching. Teaching methods is urgently needed improvements.

That is a good solution, the teaching examples and simulation experiments can be carried out by using ZEMAX. You can program the optical path, the optical element, the optical system even optical instruments in a three-dimensional entity accurately build out. Compared to the two-dimensional diagram which used in the traditional teaching, these 
examples of construction greatly improve the accuracy, which even to achieve optical accuracy. And coupled with a high degree of visualization and precision accuracy ZEMAX can ensure the effect of virtual simulation and greatly enhance the teaching efficiency.

Such as very abstract and difficult to understand the content - aberration, the use of ZEMAX make the teaching is more intuitive and easy to understand. ZEMAX allows us not only to directly see the intersection of the real light and the optical axis, and also to see the distribution of diffuse circles through the focus by using through focus spot diagrams, as shown in Figure 1. At the same time Figure 1 can also prove that the paraxial focus position (Gaussian image plane) is not the smallest diffusion circle position. When learning coma aberration, at first we use the former part of the spherical aberration for spherical aberration correction, then using the aspheric surface to make the perfect point on the shaft imaging, and further increase an extra-axial object point. Finally, we use the spot analysis to let the students understand the coma, as shown in Figure 2.

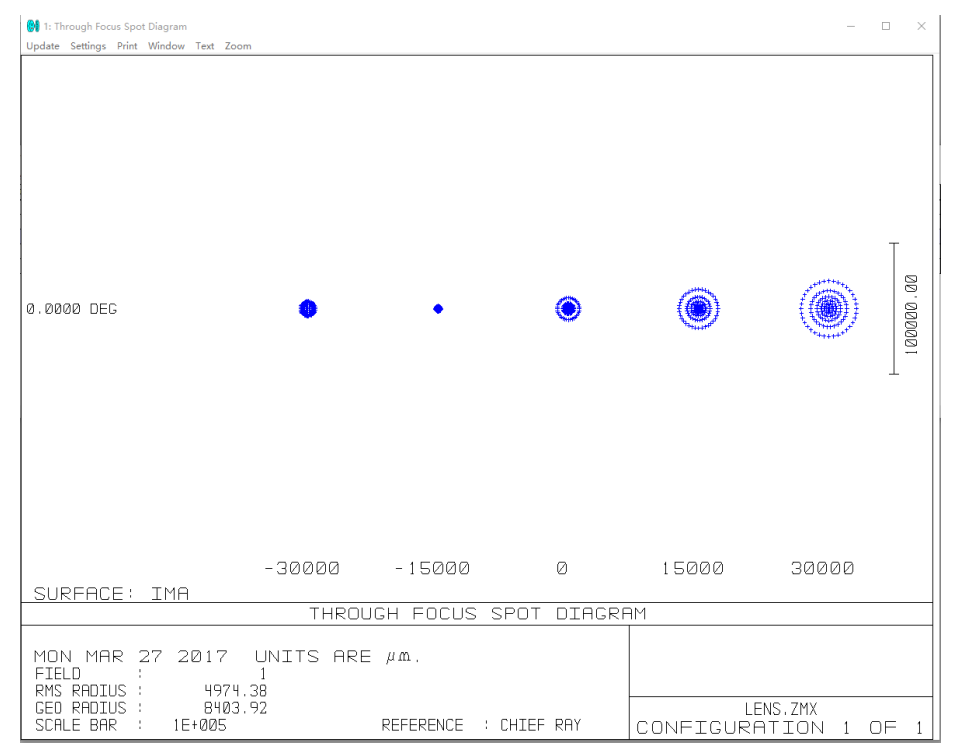

Figure 1 Through focus spot diagram of the axial point

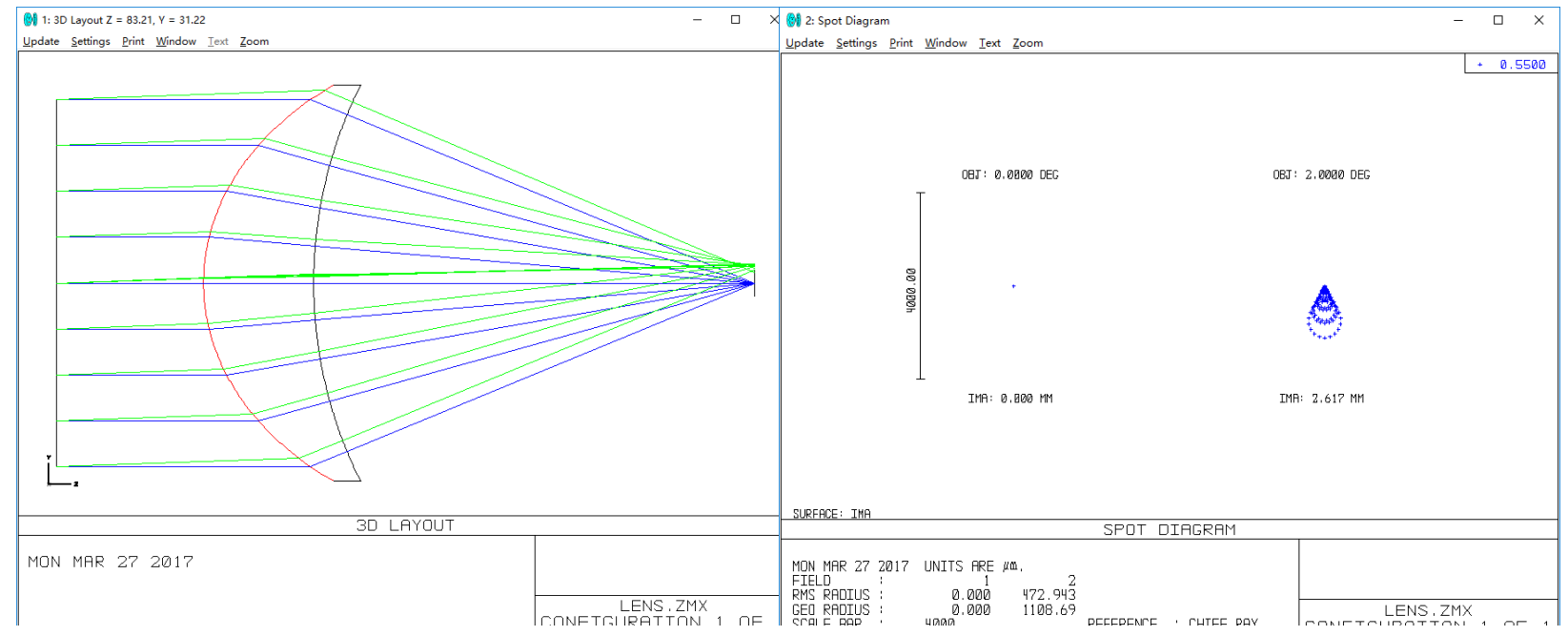

Figure 2 spot diagram of extra-axial object point 
At last, as a professional software in the field of optical engineering, ZEMAX is widely applied in scientific research, production work. Furthermore, ZEMAX also provides a platform to cultivate innovative awareness and exercise engineering capabilities, and making the learned knowledge could be applied in optical systems, optical instruments and even optoelectronic devices. So that teaching, scientific research fully convergence, to meet the needs of engineering practice.

\section{COURSE INNOVATION - BASED ON THE PHOTOELECTRIC CONTEST}

Modern optical imaging systems include lighting sources, lenses, cameras, and image processing. In teaching, one of the very important part- - How to apply optical optics to connect with the follow-up courses, highlighting the important role of lens design in system performance, and further increase the practicality of the course, interesting, is a very worthwhile thing to think about. In the application of optical design, the concept of aberration is more abstract and obscure, and the correction and optimization of aberration is the fundamental starting point and ultimate goal of design. If students do not understand the impact of aberrations on the system during the learning process, they will not accept the meaning of the application of optical design. Based on the above, the National College Students optoelectronic design competition has done a good exploration. Starting from the fifth competition, the design of the photoelectric imaging system has become a fixed topic, guiding students to establish the concept of the optical system, understand the various aspects of the important role in imaging. The fifth national photoelectric design contest - "single lens to build the best imaging system", students must make light source design, image processing to improve the image quality and resolution. In undergraduate teaching, teachers can arrange a practical design process---using different image quality lens design to build an imaging system, so that students will be more intuitive understanding of the lens design on the imaging performance. This can motivate students initiative of learning, enthusiasm and creativity, and can stimulate students' innovative thinking and innovation awareness, and promote the development of undergraduate students' optics, mechanics, electricity, numerology integrated design, development and practical ability.

\section{ASSESSMENT METHOD}

To evaluate students in a comprehensive and scientific way, the evaluation methods and standards of the school record have to be diversified, and the learning ability, practical ability and innovation ability are the most important indicators for assessing whether students are excellent. The new exams include class room discussions, flip classes, innovative thematic design and final exam with the proportion of $20 \%, 15 \%, 25 \%$ and $40 \%$ of the total scores. The assessment efforts of post-class special operations and flip classes are increased to encourage students to use new ideas to design their own works. The maritime training of the course must be avoided. The number of comprehensive, design and open engineering design questions should be increased, the factors such as emotion, learning strategy and spirit of cooperation in the process of learning will be evaluated. This new assessment methods pay more attention to what methods students have learned, what ability the students have, the evaluation changes from the assessment of record to the learning results of students. The change will guide students from the focus on examination results to focus on learning process, the learning initiative will be improved. 


\section{CONCLUSION}

This paper explores the teaching contents, teaching means, innovation and appraisal methods of "Applied Optics" course. The results show that the students' interest in learning are excited, the students' initiative and enthusiasm are improved, classroom climate is also improved. The number of students who are late is reduced. Students are willing to ask questions and say more ideas, more and more students take the initiative to participate in some research activities. The focus of the lectures is to develop students' ability which use knowledge analysis to solve the problem, rather than the formula. So that students learn the specific knowledge, and the use of knowledge at the same time. Furthermore, the students' innovative ability and scientific quality are improved.

\section{References:}

[1]. Haist, T. and Burla, A., "Learning by playing: how to create the perfect learning game for and with optics," SPIE Optical Engineering+ Applications. International Society for Optics and Photonics, 77830E-77830E-10.(2010)

[2]. Leonard, M, J. Hannahoe, R, M. and Nollmeyer, G, E., et al. "Teaching and learning geometric optics in middle school through the Turning Eyes to the Big Sky project,” Optical Engineering 52(6): 069001-069001. (2013)

[3]. Magnani, N. and Donnelly, J., "Innovative methods to teach optics in the grade 5 classroom,"Education and Training in Optics and Photonics. Optical Society of America ESD5. (2007)

[4]. Mzoughi, T. Herring, S, D. and Foley, J, T., et al. "WebTOP: A 3D interactive system for teaching and learning optics," Computers \& Education 49(1): 110-129. (2007)

[5]. Lancis, J. Fernández-Alonso, M. and Martínez-León, L., et al. "Learning to teach Optics through experiments and demonstrations," Education and Training in Optics and Photonics. Optical Society of America, EThE1. (2013)

[6]. Lakshminarayanan, V., "The human eye: A model system for teaching optics," Education and Training in Optics and Photonics. Optical Society of America, ESCB5. (2009)

[7]. Costa M, F, M., "Learning optics at basic schools by experimentation," Selected Papers on Hands-on Science, 25-28. (2008)

[8]. McDermott L, C., "Guest Comment: How we teach and how students learn—A mismatch," (1993). 